Pavla Dolezalova

\title{
Une ancienne traduction de La Nouvelle Astrée " ad usum delphini »? La double lecture du texte
}

Meta : Journal des traducteurs, 65, 3, 2020, 664-685

\section{Nová Astrea. Překlad s výkladem nejen o Seladonovi a nových Arkádiích}

Brno: Centrum pro studium demokracie a kultury 2017, 237 p.

VÁClAVA BAKEŠovÁ [bakesova@ped.muni.cz]

Masarykova univerzita, République tchèque

HTTPS://DOI.ORG/10.5817/ERB2021-2-20

La lecture d'un roman pastoral du $\mathrm{XVII}^{\mathrm{e}}$ ou du XVIII ${ }^{e}$ siècle peut-elle être compréhensible pour les lecteurs actuels ? Et peut-elle lêtre dans un milieu différent de celui de loriginal du texte et dans une langue différente? Ce sont aussi les questions que se pose Pavla Doležalová, maître de conférences à l'Institut des Langues romanes de la Faculté de Lettres de l'Université Masaryk, dans les études qui accompagnent sa traduction de La Nouvelle Astrée en tchèque (Brno 2017), mais qu'elle examine aussi dans la traduction russe de cette œuvre adaptée probablement à des projets éducatifs et publiée dès la Révolution française en Russie (Montréal 202011).

La première présentation tchèque de l’œuvre majeure d'Honoré d'Urfé faite à partir de sa version raccourcie La Nouvelle Astrée de 1712 est une initiative intéressante non seulement pour la traduction même du texte ancien, mais aussi en tant que contri-

bution importante au sein des recherches traductologiques et littéraires en République tchèque. Il s'agit d'une traduction commentée en détail avec toutes les références pertinentes, toutes les explications nécessaires, y compris toutes les précisions du sens dans les variantes éloignées de la langue actuelle. Le

1 Les informations sur l'article de Pavla Doležalová «Une ancienne traduction de La Nouvelle Astrée " ad usum delphini "? La double lecture du texte " publié dans la revue canadienne Meta : Journal des traducteurs sont disponibles sur https://www.erudit.org/fr/revues/ meta/2020-v65-n3-meta06049/1077408ar/. texte du roman est accompagné de trois études rédigées par la traductrice elle-même. Le premier texte («Pastýřská literatura jako vymírající druh, Astrea jako vyhaslá hvězda a „předpotopní“ Seladon ? ») précède la traduction d'Astrée tout en ouvrant la problématique du roman pastoral et de sa place dans le contexte historique et littéraire. Cette introduction à la lecture érudite d'une histoire d'amour des bergers Astrée et Céladon qui s'aiment malgré tous les obstacles apparaissant sur leur chemin sert de guide afin de comprendre le genre du roman pastoral et ses objectifs. Lauteure y rend plus proche aussi chacun des personnages, féminin et masculin, leur caractère et leur psychologie riche en émotions visant à atteindre le haut niveau du comportement noble par rapport aux autres personnes, humaines ou surnaturelles.

L'histoire d'Astrée et de Céladon en tchèque est suivie de létude traductologique "Překlad jako výklad » qui propose une approche herméneutique du texte. C'est une interprétation du travail du traducteur, premier lecteur du texte original et transmetteur du code d'origine dans un autre registre. Il s'agit également d'une réflexion sur le sens des traductions des œuvres anciennes en différentes langues. La dernière étude apporte une critique comparée des actualisations des mythes liés au roman pastoral d'Honoré d'Urfé. La dichotomie de l'ancien et du nouveau naboutit pas toujours à un sujet moderne et le moderne ne signifie pas toujours contemporain, 
ce qui peut compliquer les essais de réécritures de ces mythes anciens de la littérature pastorale. La méthode utilisée pour la traduction minutieuse du roman en question n'est décrite quà la fin du livre pour souligner l'expérience herméneutique du traducteur au-dessus de l'original, ainsi que du traductologue qui évalue la qualité du texte final.

Comme cette multiple lecture attentive et ces analyses des traductions de textes astréens ont éveillé un intérêt profond de Pavla Doležalová, elle a pu continuer ses recherches et faire une comparaison détaillée de La Nouvelle Astrée de 1712 traduite en russe en 1789 (et imprimée en cyrillique russe) aussi bien que réfléchir sur différentes façons de lire des textes littéraires. Dans son article de 2020, elle propose une analyse parallèle et systématique des deux textes tout en notant toutes les différences au niveau lexical, onomastique, phonétique et stylistique aussi bien qu'au niveau de la composition du texte. Elle s'intéresse aux différents changements (omissions ou/et ajouts) faits dans le texte final pour pouvoir répondre à la question : quel était le but de cette démarche qui ne garde même pas le nom du personnage principal (Céladon), devenu pourtant personnage type. Dans les tableaux avec des extraits de l'original à côté des passages en russe, elle explique en français tous les écarts du texte russe et commente les raisons possibles des décisions du traducteur.

Les recherches de Pavla Doležalová contribuent considérablement à la réflexion traductologique contemporaine et aux études du domaine de la communication interculturelle par l'intermédiaire des œuvres littéraires tout en gardant leurs racines dans sa formation littéraire. 